\title{
LES FLEURS DU MAL ANTES DE AS FLORES DO MAL: OS PRIMEIRÍSSIMOS BAUDELAIRIANOS
}

\author{
Ricardo Meirelles \\ Faculdade Capital Federal, Taboão da Serra, São Paulo, Brasil
}

\begin{abstract}
Resumo: Antes da primeira tradução completa de Les Fleurs du mal, de Charles Baudelaire, vários poetas brasileiros escolheram poemas dele para traduzir e incluir em seu repertório. Primeiro, os poemas são “aclimatados", adaptados e parafráseados por legitimar uma filiação estética, incorporados pelos poetas aos seus livros e assumidos como de sua autoria; depois, aparecem em antologias e livros exclusivos, servindo como modelo de resistência a certas novidades estéticas modernas; o amplo e intenso debate sobre a primeira recepção dos poemas de Baudelaire produziu um repertório crítico e literário composto de diversas correntes de interpretação e reconhecimento de extrema importância para a História da Literatura, como o encadeamento dos pensamentos de ASSIS (1879), CÂNDIDO (1989) e AMARAL (1996). Contudo é preciso não esquecer que existiram os "primeiríssimos baudelairianos": poetas, como o gaúcho Carlos Ferreira e o catarinense Luiz Delfino, que com sua acanhada contribuição ajudaram a garantir essa recepção e a amplitude e a intensidade desse debate.

Palavras-chave: Baudelaire; Carlos Ferreira; Luiz Delfino; Poesia; Tradução; Aclimatação.
\end{abstract}

\section{LES FLEURS DU MAL BEFORE THE FLOWERS OF EVIL: THE VERY FIRT BAUDELAIREANS}

\begin{abstract}
Before the first complete translation of Charles Baudelaire's Les Fleurs du mal, several Brazilian poets chose his poems to translate and include in your repertoire. First, the poems are «acclimatized», adapted and paraphrased for legitimizing an aesthetic affiliation, incorporated by the poets into their books and assumed as their own; then appear in exclusive
\end{abstract}


anthologies and books, serving as a model of resistance to certain modern aesthetic novelties; the wide and intense debate about the first reception of Baudelaire's poems produced a critical and literary repertoire composed of several streams of interpretation and recognition of utmost importance for the History of Literature, such as the chaining of the thoughts of ASSIS (1879), CANDIDO (1989) and AMARAL (1996). However, it is important to remember that the «very first Baudelaireans» existed: poets, like the gaucho Carlos Ferreira and the catarinense Luiz Delfino, who with their limited contribution helped to guarantee this reception and the breadth and intensity of this debate.

Keywords: Baudelaire; Carlos Ferreira; Luiz Delfino; Poetry; Translation; Acclimatization.

\section{Introdução}

Antes da publicação da primeira tradução integral do livro de Charles Baudelaire, Les fleurs du mal, em 1958, por Jammil Almansur Haddad, vários e numerosos poetas e tradutores brasileiros escolheram um ou mais poemas desse livro para traduzir e incluir em seu repertório literário. Os poemas do livro escolhido - publicado primeiro em Paris, em 1857 (edição com cem poemas), sendo que ainda receberia mais duas importantes edições aumentadas: em 1861, pelo próprio poeta; e em 1868, em edição já póstuma (contendo cento e sessenta e seis poemas) - foram traduzidos por mais de sessenta poetas brasileiros.

Ao rastrear in loco as diversas traduções, perseguindo as listas bibliográficas encontradas - que acompanhavam ora diversos estudos sobre a influência da poesia e da estética de Baudelaire, ora as traduções propriamente ditas - foi possível colecionar um grande número de poemas (cerca de dois mil) o que acabou resultando em uma interessante e profícua "baudelaireana brasileira", capaz de suscitar e diversificar em muito as visões futuras sobre essa obra francesa dentro da Literatura Brasileira.

Deparei-me assim com o mesmo dilema apresentado por Andrade Muricy em seu antológico Panorama do Movimento Simbolista Brasileiro e entendi que era necessário seguir o mesmo caminho 
do veterano historiador, visto que ainda "urgia salvar o material" (MURICY, 1952, p. 9). Afinal, tornou-se possível observar alguns aspectos relevantes dentro da própria recepção da obra estrangeira e interpretar as escolhas feitas pelos poetas brasileiros, ora como crítica - verificando se e de que forma esses poetas se alinharam, ou não, nominalmente aos princípios estéticos e literários do poeta francês - ora como realização poética independente - tomando a tradução como a expressão de uma eleição estética particular, dotada de um efeito poético próprio.

Optei em me deter em alguns pontos que considerei mais representativos, buscando sempre verificar qual a relação intertextual que as traduções poderiam ter dentro da produção da literatura brasileira e a relação direta com a influência do modelo estrangeiro na sua produção original, visto que "através das traduções é possível determinar os sintomas principais de uma influência e indicar os rumos por ela tomados" (BARBOZA, 1974, p. 30).

\section{Os primeiros baudelairianos}

O primeiro período da recepção do livro francês vai do seu lançamento, em 1857, até o fim do século XIX: Baudelaire é aclimatado (AMARAL, 1996) e seus poemas são, no mais das vezes, adaptados e parafráseados em nome da legitimação de uma filiação estética, no mínimo, discutível. Os poemas traduzidos eram incorporados pelos poetas tradutores aos seus próprios livros e quase que assumidos como de sua própria autoria, tratando mais de uma relação de aproximação ideológica do que da apresentação e divulgação de um autor estrangeiro.

Desde o início observa-se que o aspecto temático fica marcado e transformado profundamente por um naturalismo realista, característico do período e praticado pelos poetas brasileiros, como indica Bosi: 
De Baudelaire assimilam os nossos poetas realistas, Carvalho Jr. e Teófilo Dias, precisamente os traços mais sensuais, desfigurando-os por uma leitura positivista que não responde ao universo estético e religioso das Flôres do Mal. O eros baudelairiano, macerado pelo remorso e pela sombra do pecado, está longe destas expansões carnais, quando não carnívoras de Carvalho Jr.:

Como um bando voraz de lúbricas jumentas, Instintos canibais refervem-me no peito ('Antropofagia'), ou de Teófilo Dias,

... da prêsa, enfim, nos músculos cansados cravam com avidez os dentes afiados ('A Matilha'). (BOSI, 1972, p. 245-6)

Baudelaire é assim aclimatado e a abordagem dita realista ainda será perseguida ao longo do tempo por vários outros poetas, não sendo assim desfigurado, mas absorvido como parte de uma escolha coerente ao próprio ideal estético da época, deixando de lado fatalmente o universo estético religioso, que no mais seria abordado pelos simbolistas. Na verdade pode-se entender que a principal identificação desses brasileiros, os primeiros baudelairianos, com o livro francês foi, justamente, o do ideal da busca de sua própria essência. Machado de Assis, em seu estudo "A Nova Geração", publicado originalmente na Revista Brasileira (1879), faria serias críticas a essa transformação do que realmente poderia ser encontrado no livro francês, considerando-a errônea:

Quanto a Baudelaire, não sei se diga que a imitação é mais intencional do que feliz. O tom dos imitadores é demasiado cru; e, aliás, não é outra a tradição de Baudelaire entre nós. Tradição errônea. Satânico, vá; mas realista o autor de D. Juan aux Enfers e da Tristesse de la Lune! (ASSIS, 1946, p. 198) 
Esse período ainda seria marcado pela "Batalha do Parnaso", pelas primeiras manifestações parnasianas, pelas poesias militantes, socialistas e científicas. Traduzir poemas de Les Fleurs $d u$ mal chegou aqui junto com as novidades da "modernidade" e sobreviveu a todas elas, mesmo as mais renitentes, como o próprio parnasianismo. Todos queriam reproduzir Baudelaire, mesmo que não escrevessem como ele, como afirma Martins:

Imitai Baudelaire - era, com efeito, a nova palavra de ordem para a criação de uma poesia realista (e não simbolista, apesar das conotações que mais tarde se estabeleceram), poesia de temática surpreendente, menos preocupada, aliás, com as questões sociais, como desejava Teófilo Dias, do que com a descrição desassombrada e desafiadora do feio e do ignóbil. (MARTINS, 1979, p. 34)

O nome mais expressivo desse período talvez seja mesmo o de Teófilo Dias, que publicou dois livros tomados de um pessimismo "inspirado em Baudelaire" (MOISÉS, 1984, p. 471): Lira dos Verdes Anos (1876) e Cantos Tropicais (1878), onde já apareceria a tradução de "L'Albatroz". Traduziu também mais oito poemas ("Dom Juan nos infernos", "O veneno", "O espectro", "A música", "O sino", "Manhã de inverno", "A fonte de sangue", "O cachimbo") em seu Fanfarras (1882) e ainda mais um, "Confidências", que apareceria em um artigo de jornal de Félix Pacheco, em 1934, somando dez poemas.

A seqüência de seus livros demonstra uma evolução: de epígono romântico, adepto dos modismos líricos, passa a realista, tomado de um naturalismo sensual e social, para por fim, no seu melhor livro, mostrar todo seu talento. Fortemente marcado por Les Fleurs du mal, Fanfarras prolonga a lição do mestre francês (MOISÉS, 1984, p. 415). O livro está dividido em duas partes e traz na primeira, "Flores Funestas" - a segunda é "Revolta" - as traduções de Baudelaire, junto com outros poemas, sendo, segundo Amaral, 
"provavelmente, o maior conjunto de poemas produzidos sob a influência de Baudelaire na literatura brasileira do século XIX" (AMARAL, 1996, p. 121).

Entretanto, antes de Teófilo Dias e dos "Primeiros Baudelairianos" (CÂNDIDO, 1989, p. 23), outros poetas também se aventuraram a traduzir poemas de Baudelaire e não devem ser esquecidos para uma boa compreensão da História da Literatura Brasileira, tendo em vista que "cada vez mais se tornam evidentes a importância documental, a significação sintomática expressiva dos secundários e dos epígonos" (MURICY, 1952, p. 14). É o caso dos primeiríssimos baudelairianos Carlos Ferreira e Luiz Delfino.

\section{Carlos Ferreira}

É o gaúcho Carlos Augusto Ferreira (1844-1913), tido como um dos últimos românticos e quase esquecido pela crítica em geral, a apresentar a tradução publicada de um poema de Baudelaire mais antiga: "Modulações", tradução de "Le Balcon", encontrada no seu terceiro livro, Alciones, publicado em 1872. Seus outros livros foram Cânticos Juvenis (1867), Rosas loucas (1868), Redivivas (1881) - livro no qual saiu publicada a tradução de "Moesta et errabunda" - e Plumas ao vento (1908) (BAUMGARTEN, 1997, p. 152).

Notadamente romântico até o fim de sua carreira literária, "poeta-ourives, futuro autor de versos hugoanos, vai a São Paulo, saindo de sua terra natal, Porto Alegre, às expensas de D. Pedro" (PICCHIO, 1997. p 174), uma espécie de poeta financiado pelo governo que, apesar de demonstrar intimidade com as mudanças que se passavam, não mudou sua maneira de escrever, e por isso, talvez, o pouco apreço da crítica. Ferreira teria ajudado a marginalizar os versos de Baudelaire, mas é certo que nele já se sente a modernidade que virá: “ou já descobrira Baudelaire antes de 1872, ou pressentia, na multiplicidade temática de sua cosmovisão, o horizonte novo que As Flores do Mal viriam a rasgar" (MOISES, 1984, p. 275). Sobre essa influência, ainda observa Moisés: 
A presença do autor dAs Flores do Mal no lirismo de Carlos Ferreira se, de um lado, significa precoce adesão à voz do mestre alquímico da poesia moderna, de outro, não deve surpreender: o pólo melancolizante e funéreo da diç̧ão do poeta brasileiro guarda uma analogia latente com a do francês. (MOISES, 1984, p. 274.)

Sua tradução de "Le Balcon", "Modulações", classificada no subtítulo como "imitação de Baudelaire” pelo próprio poeta, aproxima-se muito do poema francês: tem a mesma estrutura formal e segue, além dos aspectos rítmicos e métricos, o tom melancólico, nostálgico e evocativo, tão caro a Baudelaire. Amaral, no entanto, vê a seguinte diferença: “'Le Balcon' concentra-se na repercussão da lembrança amorosa na alma do poeta; 'Modulações' procura recuperar as reações femininas e acaba por fazer presente uma pálida e ansiosa musa romântica" (AMARAL, 1996, p. 38).

De fato, com uma estrofe a mais - na verdade a repetição da primeira com algumas modificações nos segundo e terceiro versos - o poeta parece querer fechar um ciclo, opondo assim "Saudosa inspiração da lúcida poesia! / Que é da quadra feliz do affecto delirante", a "Cadente inspiração da lúcida poesia! / Não vês? eu góso ainda a febre delirante", como se mesmo depois de realizada a proeza da lembrança ainda se dá conta que delira, ou seja se dá conta da sua inspiração delirante.

É certo que a poesia de Ferreira é muito menos ardente que a de Baudelaire, como se pode ver principalmente pela substituição dos versos franceses "O toi, tous mes plaisirs! ô toi, tous mes devoirs! / Tu te rappelleras la beauté des caresses" pelos versos citados anteriormente. Os prazeres e deveres evocados na lembrança passam a ser algo como se o poeta se denunciasse, afirmando primeiro que é lúcida a sua inspiração - que parte de outro poema, "denunciando" a sua tradução - e depois se desmentisse ou se resignasse dizendo que afinal ainda sofre a febre delirante - que pôde gerar tal poema.

Ferreira traduziu também "Moesta et errabunda", poema que por sua vez me parece muito mais intrigante. Publicada no livro 
Redivivas, $\log$ abaixo do título da tradução vai a data de 1871 , data da provável elaboração do poema, e numa nota o poeta já avisa que "esta poesia foi escripta sobre uma de Charles Baudelaire, do conhecido livro Flores do Mal". Ferreira foi o único poeta a escolher esse poema especificamente, mas essa escolha já serviria para definir e compreender a linha adotada pelos demais baudelairianos brasileiros.

"Moesta et errabunda" contém uma série de elementos temáticos que vão formar uma tópica muito forte ao longo da recepção do livro francês no Brasil: a paisagem tropical como o paraíso ideal e inalcançável, em oposição à cidade escura e inexpugnável - ideal e spleen. Esse paraíso não é inalcançável meramente no plano espacial, mas, mais do que isso, já vem impregnado do mesmo tédio absoluto que envolve o poeta e o faz pressentir que por mais puras que um dia já foram as aspirações humanas, não mais satisfazem aquele espírito elevado. Não é só uma questão de impossibilidade, mas também de desencanto e desapego.

Fica então apenas no ideal esse paraíso, como se lê na sexta estrofe: "L'innocent paradis, plein de plaisirs furtifs,", não se pode encontrá-lo geograficamente, pois "Est-il déjà plus loin que l'Inde et que la Chine"; pergunta então o poeta se esse paraíso está ao alcance de gritos agudos, "d'une voix argentine", parecendo já ciente da impossibilidade de ser ouvido. Ouso dizer que esse grito foi de certa forma ouvido por Ferreira: onde mais poderia ser esse paraíso perfumado, inocente e cheio de prazeres furtivos e ocultos senão aqui mesmo no Rio de Janeiro, a "cidade maravilhosa"? Não é à toa que os poemas de Baudelaire mais traduzidos no Brasil foram justamente L'Albatros, L'homme et la Mer e Parfum Exotique (MEIRELLES, 2003).

Pode-se ver isso logo nos primeiros versos: "Bem sei! teu coração é todo primaveras / $\mathrm{E}$ foge ás vezes, Lucia, aos mares da cidade / Para outro mar, além, povoado de chimeras". Ferreira não ouve uma canção, mas sim "um poema immenso e terno", novamente se denuncia como um tradutor a ouvir um poema original.

Cad. Trad., Florianópolis, v. 38, $\mathrm{n}^{0}$ esp. Baudelaire 150 anos, p. 113-134, ago-dez, 2018 
Apesar de já demonstrar estar atento às novas mudanças, essas alterações parecem vir sempre no sentido de atenuar as imagens ardentes do poema francês, padecendo de um romantismo muito mais conservador, descrevendo a musa assim muito mais triste que erradia. Isso, de certa forma, confirma outro comentário de Moisés:

\begin{abstract}
Nem o ar à Cesário Verde, de 'Horas Mortas', 'Alta Escola', 'A Baronesa', nem o emprego de vocábulos em moda, como 'transformismo' ou 'mônada', nem o reflexo de Baudelaire em 'Moesta et errabunda', e nem os temas helênicos e pátrios, caros ao Parnasianismo, que despontam em $\mathrm{Plu}$ mas ao Vento, dissipam os vapores românticos que embriagavam o poeta. (MOISES, 1984, p. 276.)
\end{abstract}

É assim então, como um dos últimos românticos, que Carlos Ferreira publica o primeiro poema do livro de Baudelaire no Brasil, lidando ainda com elementos constitutivos muito mais do "ideal" baudelairiano, sendo que é significativo, num primeiro momento, que seja a eleição desses elementos pelos poetas brasileiros o principal atrativo do livro estrangeiro.

\title{
4. Luiz Delfino
}

Outro dos primeiros tradutores de Les Fleurs du mal é Luiz Delfino dos Santos (1834-1910), poeta catarinense, médico e senador da república, sempre muito considerado pelos estudiosos e, a despeito disso, não tendo despertado a atenção crítica que merece.

Demonstrando já um engajamento com as questões sociais "Delfino reflete, em 1884, o novo clima social, divulgando alguns poemas abolicionistas, (...), em que é, talvez, menos dramático e eloqüente que Castro Alves", (MARTINS, 1979, p. 210). O crítico Clóvis Beviláqua, ao tratar do naturalismo corrente na época de Delfino, chegou a classificá-lo como o "chefe unanimemente eleito 
da escola hoje dominante no Rio de Janeiro" (Apud MARTINS, 1979, p. 142); e Picchio chama-o de "o camaleão de ouro das letras brasileiras” (PICCHIO, 1997, p. 287).

Silvio Romero, "alegando existir a opinião de que Machado de Assis e Luiz Delfino eram 'legítimos representantes do Naturalismo no Brasil'", em $O$ Naturalismo em Literatura, chega a atacá-lo, classificando-o como um dos "escritores de ordem terciária" (MARTINS, 1979, p. 143). Apesar das controversas críticas, seus poemas eram muito lidos, constituindo um lugar de destaque no panorama literário da época. Em 1885

sabe-se que o periódico A Semana, de Valentim Magalhães, abriu um concurso para a escolha do maior poeta do Brasil. $\mathrm{O}$ resultado, anunciado em junho, dando o primeiro lugar a Gonçalves Dias, o segundo a Castro Alves e o terceiro a Luís Delfino, confirmava a sedimentação do gosto em favor de uma poesia já conhecida e aceita; o parnasianismo ainda tinha que fazer o seu caminho (MARTINS, 1979, p. 216).

Apesar do notório reconhecimento enquanto poeta romântico, muito caro ao público leitor, "Luiz Delfino, com os seus 'soberbos sonetos', também concorrera para a lenta implantação da nova escola [o Parnasianismo]" (MARTINS, 1979, p. 155): tomado como um poeta de transição do romantismo para o parnasianismo e o simbolismo, mas que seria, na época, ainda romântico, assim como Carlos Ferreira.

Além de traduzir também poemas de Hugo, Gautier, Byron, Heine e Petrarca, sua vasta obra foi publicada originalmente em jornais e revistas no Rio de Janeiro, e só foi recolhida por seu filho em livro postumamente (alguns publicados pela Editora Pongetti, outros pela Litotipografia Pimenta de Melo) entre 1927 e 1942: Algas e Musgos (1927), Poemas (1928), Poesias Líricas (1934), Íntimas e Aspásicas (1935), A Angústia do Infinito (1936), Atlante Esmagado (1936), Rosas Negras (1938), Arcos de Triunfo (1939), Posse Absoluta (1941),

Cad. Trad., Florianópolis, v. 38, $\mathrm{n}^{0}$ esp. Baudelaire 150 anos, p. 113-134, ago-dez, 2018 
O Cristo e a Adúltera (1941) - livro que contém suas traduções - e ainda Imortalidades (1941-1942) (SANTOS, 2001).

"O veneno", a única tradução de Delfino do livro de Baudelaire, apareceria apenas em 1934, mas datada de 1871, acompanhada de um pequeno artigo, no Jornal do Comércio de Félix Pacheco (PACHECO, 1934, p. 2). O poema francês, "Le Poison", foi pouco traduzido no Brasil, sendo escolhido apenas por Delfino e Teófilo Dias. Esses poetas estão cronologicamente muito próximos um do outro - o primeiro dataria seu poema em 1871 e o segundo, publicaria o seu em 1882. No entanto, chamam muita a atenção as diferenças entre as duas traduções, que são muito interessantes e reafirmam algumas idéias, primeiro sobre a aclimatação do texto estrangeiro, depois, de como a criatividade, guiada por um contexto estético, dirige o conceito de fidelidade.

De fato o poema "Le Poison" se divide em duas partes, cada uma com uma cor, tempo, e movimento particulares e antagônicos, mas não excludentes, que se complementam como o spleen - vermelho e ilimitado - e o ideal - verde e fugaz. Mas o aspecto moderno que salta aos olhos é o grotesco constatado na finitude humana: é só através do veneno que o poeta se dá conta de si mesmo, para depois, ao colher a saliva da musa, esquecer a si mesmo. $\mathrm{O}$ enlouquecimento e o êxtase são obtidos através de uma overdose de realidade: nada vale mais do que essa mulher de verdade, tão real quanto o próprio poeta.

Se por um lado se Delfino e Dias elegeram esses elementos como os mais significativos dentro da leitura, por outro lado não os têm como absolutos, visto que a manifestação poética se dá exatamente no instante da leitura do poema, o que permite vislumbrar com certa isenção e com o mesmo distanciamento dispensado ao poema francês, seus respectivos poemas brasileiros. Na segunda parte do poema - introduzida por uma construção equivalente: "E nada disto vale" - estranhamente não se vê justamente o "poison" do título, Delfino o destila em "tóxico horrendo" para depois surpreender com o verso "Nada vale a baba de tua boca" - muito mais realista e escatológico, mais natural, exótico e brasileiro, que se 
manifesta significativamente dentro da idéia de comunidade interpretativa (ARROJO, 1993, p. 98).

Dias, em contraposição ao apresentado Delfino, apresenta, em sua tradução, os versos: "Nada ao teu beijo iguala a pressão indizível". Antonio Candido, que considerou essa tradução "apenas razoável”, já chama a atenção para a mudança efetuada pelo poeta brasileiro, dizendo que "sempre que precisou traduzir 'salive' [...], Teófilo substituiu-a por 'pressão', que nada diz de positivo; para Baudelaire é justamente a saliva que consubstancia, como um 'filtro', todo o veneno difundido no poema" (DIAS, 1960, p.45). Dias assim não segue o mesmo princípio que Delfino, preferindo uma estética mais amena a um naturalismo exacerbado.

Comparando essas duas traduções do mesmo poema, pode-se observar em Delfino e em Dias duas distintas tendências tradutórias: a primeira, de provocar de fato um estranhamento, evidenciando as características particulares do estrangeiro, e de certa forma se filiando a elas, ao mesmo tempo em que as elege dentro de uma ideologia naturalista, coerente com seu próprio processo criativo. Enquanto a segunda, notoriamente poderia ser descrita simplesmente por belle infidèle, numa postura regular de submissão aos métodos do modelo francês, procurando tornar palatável e absorvível o grotesco da modernidade apresentada.

Luiz Delfino pode se enquadrar certamente entre os aclimatadores e os imitadores, capazes de transformar o próprio Baudelaire a fim de fazê-lo parecer mais consigo mesmo. Resta mais uma interpretação, manifestada aqui agora como tradução, mas que não deixa de ser uma crítica, pois realiza as observações e as identificações sentidas pelo poeta e, mais do que isso, registra suas escolhas, dentro de uma intenção estética própria e inerente.

Restaria ainda uma pergunta: deve a tradução ser abordada no contexto histórico da data de sua elaboração, que é quando o poeta está incorporado pelo espírito de sua época, ou deve ser lida dentro da "comunidade interpretativa" (ARROJO, 1993, p. 98), da sua publicação em livro, quando o poema pôde ser lido e realizado de fato pelo leitor? Inevitavelmente o estudioso deve se ater ao 
mesmo critério empregado na leitura do poema francês, bem como na leitura de qualquer poema, visto que não se pode escapar às circunstâncias que cercam a si mesmo.

\section{Considerações finais}

Este trabalho parte da reunião das traduções dos poemas do livro Les Fleurs du mal, do poeta francês Charles Baudelaire, publicadas no Brasil em meio impresso - livros e periódicos - e procura refletir tanto sobre a relevância e o diálogo dessas traduções dentro da História da Literatura Brasileira, quanto sobre qual é o seu posicionamento em relação a esse clássico universal da literatura francesa.

Primeiro, em minha dissertação, Entre brumas e chuvas: tradução e influência literária (2003), e depois, em minha tese, "Les Fleurs du mal" no Brasil: traduções (2010), discuti e considerei o papel da tradução poética dentro da História da Literatura Brasileira e a sua influência estética, observando específica e atentamente a recepção desses poemas escritos por Baudelaire; ao longo desses estudos, procurei questionar alguns métodos e teorias da tradução poética, observando principalmente autores brasileiros, e comparando traduções de vários tradutores ao longo do tempo, sempre levando em conta aspectos lingüísticos, históricos e culturais que poderiam se depreender de cada texto.

Além do resgate historiográfico promovido, recuperando algumas importantes e significativas leituras da obra francesa, comparando suas traduções com outras produzidas ao longo do tempo, vislumbro não uma evolução, mas sim uma diferenciação entre as abordagens tradutórias, construídas sempre dentro de seu momento estético, histórico e ideológico, que está nelas refletido, inevitavelmente.

Nesse sentido, a leitura que se deseja, hoje em dia, é a da simultaneidade, que atinja uma "cadeia de recepções", principalmente em questões de tradução, conceito estreitamente ligado à idéia de comunicação e interação. 
A implicação histórica manifesta-se na possibilidade de, numa cadeia de recepções, a compreensão dos primeiros leitores ter continuidade e enriquecer-se de geração em geração, decidindo, assim, o próprio significado histórico de uma obra e tornando visível sua qualidade estética. (JAUSS, 1994, p. 23)

A leitura do máximo possível de traduções de um texto só pode ser profícua e benéfica, completando-se mutuamente enquanto aproxima e afasta o leitor ora do texto original, ora da própria literatura, adimitindo que esse processo não é nunca estático, é sempre uma dinâmica dialética entre levar o leitor local à cultura estrangeira e trazer o texto estrangeiro à cultura local, não se podendo optar por uma dessas travessias, a tradução é o simultâneo ir e vir.

Concluindo, seria correto afirmar que o livro de Charles Baudelaire, Les Fleurs $d u$ mal, teve uma ampla e intensa recepção mesmo antes de sua publicação integral no Brasil, gerando diversas correntes de interpretação e reconhecimento e produzindo um repertório crítico e literário de extrema importância para a História da Literatura Brasileira. Contudo é preciso não esquecer que existiram os "primeiríssimos baudelairianos": poetas, como o gaúcho Carlos Ferreira e o catarinense Luiz Delfino, que com sua acanhada contribuição ajudaram a garantir essa recepção e a amplitude e a intensidade desse debate.

\section{Referências}

AMARAL, Glória Carneiro do. Aclimatando Baudelaire. São Paulo: Annablume, 1996. (Parcours) 
ARROJO, Rosemary. Tradução, Desconstrução e Psicanálise. Rio de Janeiro: Imago, 1993. (Biblioteca Pierre Menard)

ASSIS, Machado de. A Nova Geração. In. . Crítica Literária. Rio de Janeiro. Clássicos Jackson, 1946.

BARBOZA, Onédia Célia de Carvalho. Byron no Brasil: traduções. São Paulo: Ática, 1974. (Ensaios, 12)

BAUDELAIRE, Charles. As Flores do Mal. Trad., introd. e notas de Jamil Mansur Haddad. São Paulo: Difel, 1958.

. Oeuvres Complètes. Texte établi, présenté et annoté par Claude Pichois. Paris: Gallimard, 1975.

BAUMGARTEN, Carlos Alexandre. A Crítica Literária no Rio Grande do Sul: do romantismo ao modernismo. Porto Alegre: IEL, EDIPUCRS, 1997.

BOSI, Alfredo. História concisa da literatura brasileira. 2a. edição. São Paulo: Cultrix, 1972.

CANDIDO, Antonio. Os primeiros baudelairianos. In: . A educação pela noite. São Paulo: Ática, 1989.

DIAS, Teófilo. Cantos Tropicais. São Paulo: Dolivaes Nunes, 1876.

. Lira dos Verdes Anos. São Paulo: Dolivaes Nunes, 1878.

. Fanfarras. São Paulo: Dolivaes Nunes, 1882.

. A comédia dos deuses. São Paulo: Dolivaes Nunes, 1888.

. Poesias Escolhidas. Sel., intr. e notas por Antonio Candido. São Paulo: Conselho Estadual de Cultura - Comissão de Literatura, 1960. 
FERREIRA, Carlos. Cânticos Juvenis. Porto Alegre: s.ed., 1867.

. Rosas loucas. São Paulo: Casa Garreaux, 1868

. Alciones. Rio de Janeiro: J. T. P. Soares, 1872.

. Redivivas. Poesias. Prólogo de F. Quirino dos Santos e Julio Ribeiro.

Campinas: Typ. da "Gazeta de Campinas", 1881.

. Feituras e feições. Campinas: Typ. Livro Azul, 1905.

. Plumas ao vento. Campinas: Casa Geunaud, 1908.

. Rimas e prosa. Campinas: Gráfica Filial Canton, 1910.

JAUSS, Hans Robert. A História da Literatura como provocação à Teoria Literária. Tradução de Sérgio Tellaroli. São Paulo: Brasiliense, 1994.

MARTINS, Wilson. História da Inteligência Brasileira. São Paulo: Cultrix, 1979.

MEIRELLES, Ricardo. Entre brumas e chuvas: tradução e influência literária. Dissertação (mestrado) - Universidade Estadual de Campinas, Instituto de Estudos da Linguagem: Campinas, 2003.

. "Les Fleurs du mal" no Brasil: traduções. 2010. Tese (doutorado) Faculdade de Filosofia, Letras e Ciências Humanas. Universidade de São Paulo, São Paulo, 2010.

MOISES, Massaud. História da Literatura Brasileira. São Paulo: Cultrix, Edusp, 1984. Vol 2 "Romantismo Realismo". p. 274.

MURICY, Andrade. Panorama do Movimento Simbolista Brasileiro. Rio de Janeiro: Instituto Nacional do Livro, 1952. 
PACHECO, Felix. "Baudelaire e Luís Delfino". Jornal do comércio, Rio de Janeiro, 24.12.1934. p. 2.

PICCHIO, Luciana Stegagno. História da literatura brasileira. Rio de Janeiro: Nova Aguilar, 1997.

SANTOS, Luiz Delfino dos. Poesia Completa. org. de Lauro Junkes. Florianópolis: ACL, 2001, 2 v.

Recebido em: 21/09/2018

Aceito em: 19/10/2018 Publicado em dezembro de 2018

Ricardo Meirelles. Email: meirelles.ricardo@gmail.com ORCID: https://orcid.org/0000-0002-9167-5526 


\section{APÊNDICE}

Modulações (poema de Carlos Ferreira) (inspiração de Baudelaire)

Debil visão divina! Ó minha dôce amante, Saudosa inspiração da lucida poesia!

Que é da quadra feliz do affecto delirante

D'aquelle immenso amor de immensa melodia, 05 Debil visão divina, ó minha dôce amante?... 
Á tarde quando o sol morria no horizonte

Olhavamos o céo sósinhos na janella...

Tinhas o seio em ancia, a pallidez na fronte

E eu cingia-te as mãos, as tuas mãos, ó bella,

10 Á tarde quando o sol... morria no horizonte.

Como é sublime o céo por tarde estiva e quente!

O coração palpita e não se prostra enxangue;

Lembras-te ainda, amor? eu exclamava ardente

Como que respirando odores de teu sangue:

15 Como é sublime o céo por tarde estiva e quente!

Quando descia emfim da noite o negro manto

Eu via inda na treva o brilho d'esse olhar!...

Como eu bebia então o effluvio d'esse encanto!

Como eu sabia então teus lindos pés beijar

20 Quando descia emfim da noite o negro manto

Sei evocar, bem vês, os dias meus ditosos...

Meu saudoso passado esconde-se em teus braços.

Porque querer gosar teus beijos languorosos?

Porque querer gosar teus lubricos abraços?

25 Sei evocar, bem vês, os dias meus ditosos...

Ó perfumes! amor! ó beijos infinitos!

Vêr-vos-hei renascer em minha mente em chamma,

Como após tantos sóes renascem sóes bemditos,

Como após uma flamma atêa-se outra flamma,

30 Ó perfumes! amor! ó beijos infinitos!

Debil visão divina! Ó minha dôce amante,

Cadente inspiração da lucida poesia!

Não vês? eu góso ainda a febre delirante

D'aquelle eterno amor de eterna melodia, 
35 Debil visão divina, ó minha dôce amante!...

Moesta et errabunda (poema de Carlos Ferreira) (1871)

Bem sei! teu coração é todo primaveras E foge ás vezes, Lucia, aos mares da cidade Para outro mar, além, povoado de chimeras, Profundo, bello, azul, da côr da virgindade...

05 Bem sei! teu coração é todo primaveras!...

O mar, o vasto mar que embala as nossas lidas!... Quem lhe daria a elle - o poeta grande e eterno Esse dom de arrancar das cordas doloridas Do vento do deserto, um poema immenso e terno, 10 Ao mar, ao vasto mar que embala as nossas lidas?

Transporta-me wagon! eleva-me fragata! Longe! longe! que aqui - só vejo lama e pranto. Ó Lucia, vem commigo! Este ar cruel nos mata, Um sonho no oceano é bello, enorme e santo...

15 Transporta-me wagon! eleva-me fragata!

Como tão longe estás, ó mundo perfumado Onde brilha o amor por entre azul e estrellas, Onde tudo convida a amar e ser amado, Onde a paixão desaba em lubricas procellas!...

20 Como tão longe estás, ó mundo perfumado!...

Saltae do rubro leito, auroras purpurinas,

Canções da juventude... ó sonhos! beijos, flores!

Geme o violão sentido ás brisas da collina... 
Desperta, ó natureza, e afoga-me de amores,

25 Saltae do rubro leito, auroras purpurinas!...

Esse sonhado céo de tanto goso occulto

Mais longe inda será do que a India ou a China?

Pois heide voar a elle, e lá verei teu vulto

Ó Lucia! e escutar a tua voz divina

30 - Esse sonhado céo de tanto goso occulto!...

O veneno (poema de Luiz Delfino)

Veste o vinho a mais sórdida palhoça

De um luxo milagroso;

E no oiro de um vapor rubro, que engrossa,

Faz surgir mais de um pórtico que roça,

05 Como um sol, que descamba, um céo nevoso.

Dilata o ópio o cyclo do impossível:

Alonga o illimitado;

Afunda o tempo, e o gôso inexcedível;

E de um morno prazer, negro, terrível

10 A alma encharca, inda além do que lhe é dado.

E nada disto vale o toxico horrendo,

Que teus olhos distillam,

Lago amargo, em que cae a alma tremendo;

Abysmo, em que meus sonhos, que scintillam,

15 Como em verde lagôa, estão bebendo.

Nada vale a baba de tua bocca,

Que tem prodigio enorme:

Ahi sem pena uma alma se suffoca:

Ahi no olvido esmaia, e inerme toca; 
20 E a morte acha-a na lama, em que ela dorme...

O veneno (poema de Teófilo Dias)

O vinho veste e enfeita a cabana mais nua

Com pompa milagrosa,

E faz surgir mais de uma Alhambra fabulosa

Que em seu vapor flutua

05 Como sol no poente, em tarde nebulosa.

O ópio faz crescer o ilimitado; o imenso

Aumenta; e tem poder

De eliminar o tempo: e, cavando o prazer,

De um fundo gôzo intenso

10 Inunda a alma além do que pode conter.

Mas nada disto vale o veneno, que mana

Teu olhar, que seduz,

O lago,aonde a febre os meus sonhos conduz,

Fremente caravana

15 Que a sêde vai matar nesse abismo de luz.

Nada ao teu beijo iguala a pressão indizível

Que morde, em que mes estorço,

Que afoga-me no olvido a alma, sem remorso,

E em delíquio terrível

20 Do môrno mar da morte a embala sôbre o dorso. 